\title{
Outcomes of Short Synacthen Test in a University Teaching Hospital: Are Baseline and Time 30 minutes Sufficient?
}

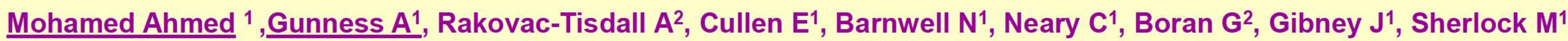
Departments of Endocrinology ${ }^{1}$ and Chemical Pathology2, The Adelaide and Meath Hospital, incorporating the National Children's Hospital, Tallaght, Dublin, Ireland.

\section{OBJECTIVES}

Short synacthen test (SST) has become the standard method of assessing the hypothalamic-pituitary-adrenal (HPA) axis. However, there are still variances in practice with regards to performing and interpreting this test in particular the need for measuring cortisol level at both time 30 and 60 minutes.

\section{METHODS}

A retrospective review of 500 consecutive SST performed at a University teaching Hospital in Dublin between 2005 and 2012.

Serum cortisol was measured at time 0,30 , and 60 minutes following a standard injection of $250 \mathrm{mcg}$ of synacthen.

A cortisol level of $>500 \mathrm{nmol} / \mathrm{L}$ was considered adequate to out rule adrenal insufficiency.

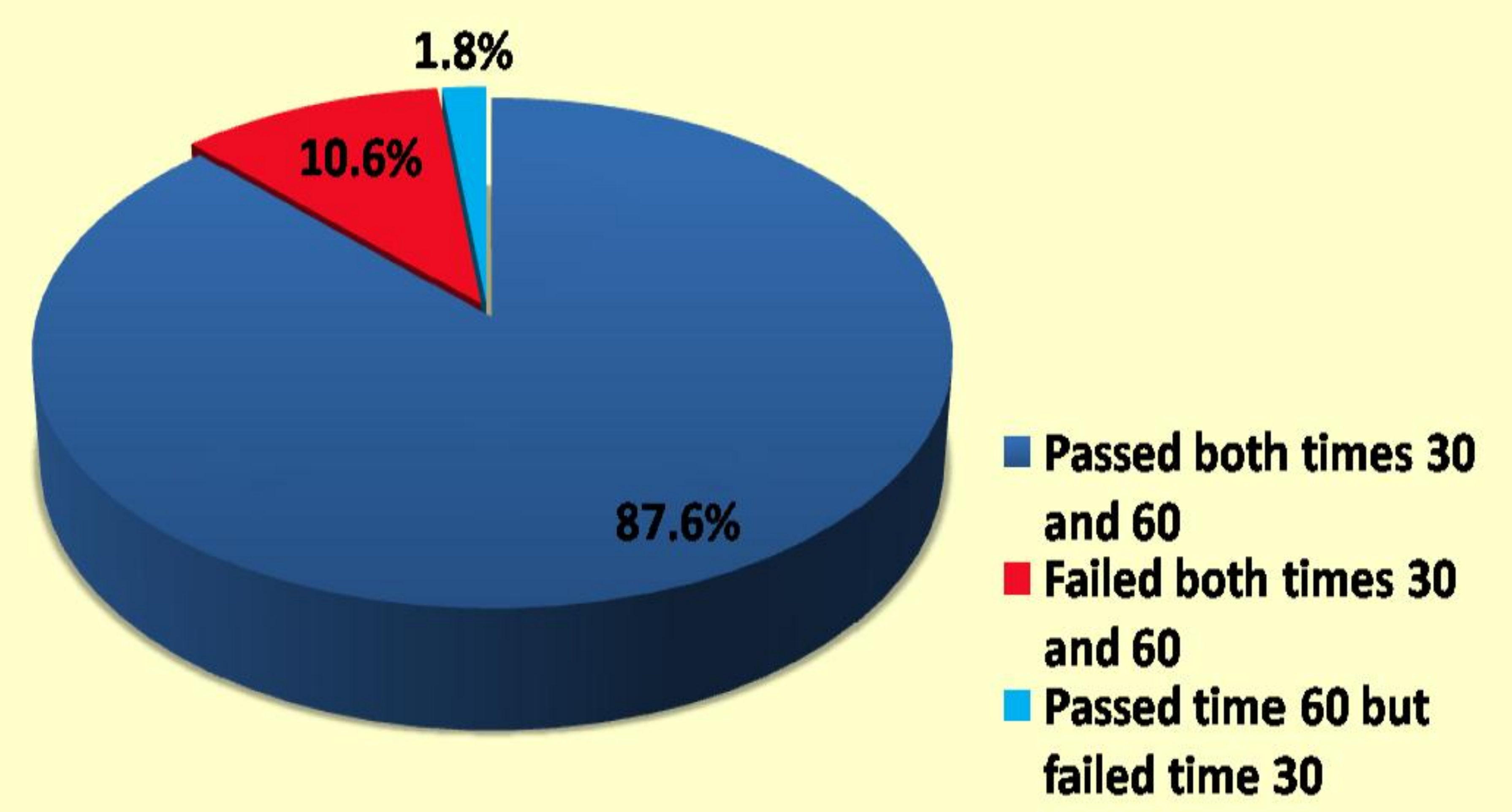

Figure 1 :Outcomes of Short Synacthen test.
Table 1: Random cortisol and serum Sodium levels in the preceding 6 months in relation to SST outcomes.

\begin{tabular}{|l|l|l|l|}
\hline \multirow{2}{*}{ Parameters } & \multicolumn{2}{|c|}{ SST Outcome } & \multirow{2}{*}{ P Value } \\
\cline { 2 - 3 } & Passed Test & Failed Test & \\
\hline $\begin{array}{l}\text { Mean (SD) random cortisol in the } \\
\text { preceding } \mathbf{6} \text { months (nmol/L) }\end{array}$ & $367.6( \pm 195.7)$ & $133.5( \pm 81.8)$ & $P<0.01$ \\
\hline Random cortisol $>\mathbf{4 0 0} \mathbf{~ n m o l} / \mathrm{L}$ & $72 / 72(100 \%)$ & $0 / 72(0 \%)$ & $P<0.01$ \\
\hline Random cortisol $<\mathbf{1 0 0 ~} \mathbf{n m o l} / \mathrm{L}$ & $8 / 24(33.3 \%)$ & $16 / 24(66.7 \%)$ & $P<0.01$ \\
\hline $\begin{array}{l}\text { Serum } \mathbf{N a}<135 \mathrm{nmol} / \mathrm{L} \text { in the } \\
\text { preceding } 6 \text { months }\end{array}$ & $189 / 437(43 \%)$ & $36 / 63(58 \%)$ & $P<0.05$ \\
\hline
\end{tabular}

\section{RESULTS}

Out of 500 patients, 297 (59.4\%) were females, and the average age was $57.4 \pm 19.3$ years.

$215(43 \%)$ of subjects had at least one random cortisol level checked in the preceding 6 months prior to the synacthen test date, and the mean random cortisol for those who passed the test was $367.6 \pm 195.7 \mathrm{nmol} / \mathrm{L}$ compared to $133.5 \pm 81.8$ in those who failed it, $p<0.01$.

$225(45 \%)$ of patients had at least one low serum sodium ( $<135 \mathrm{nmol} / \mathrm{L})$ during the 6 months prior to test.

Hyponatraemia was more prevalent in those who failed the test compared to those with adequate cortisol response $(58 \%$ vs $43 \%, p<0.05)$.

$438(87.6 \%)$ patients passed their SST at both time 30 and 60 minutes and $53(10.6 \%)$ failed it.

In 9 cases only $(1.8 \%)$, the peak value of $>500 \mathrm{nmol} / \mathrm{L}$ was achieved at time 60 but not at time 30 minutes.

\section{CONCLUSIONS}

Our data shows that patients with low random cortisol and hyponatraemia in the 6 months prior to the SST are likely to fail it.

Measuring the baseline and time 30 minutes cortisol will lead to the correct diagnosis in over $98 \%$ of cases.

Checking cortisol level at time 60 is of little added value in the majority of cases. 